\title{
Levantamento de investigações sobre a Educação de Jovens e Adultos na Revista Boletim de Educação Matemática-BOLEMA
}

Anildo Soares Flôr ${ }^{1}$

Edvonete Souza de Alencar ${ }^{2}$

Alessandra Cristina Furtado ${ }^{3}$

\section{Resumo}

Este artigo objetiva promover um estudo referente às publicações realizadas pelo BOLEMA - Boletim de Educação Matemática, entre os anos de 2009 e 2018. Verificou-se a existência de 22 trabalhos voltados para pesquisas sobre a Educação Matemática na Educação de Jovens e Adultos. Por meio deste levantamento, foi possível identificar as principais instituições e pesquisadores que investigam esta área e publicam parte de seus trabalhos na referida biblioteca eletrônica. Pretendeu-se, ainda, fazer uma breve análise dos trabalhos vinculados neste meio de comunicação, procurando traçar um panorama sobre o tema estudado. Também se fez necessário um estudo das políticas públicas brasileiras com o objetivo de oferecer, uma reflexão sobre as práticas pedagógicas na Educação de Jovens e Adultos.

Palavras-chave: Educação Matemática, Educação de Jovens e Adultos, Estudos.

\section{Survey of investigations on Youth and Adult Education in the Boletim de Educação Matemática-BOLEMA} magazine

\section{Abstract}

This article aims to promote a study related to publications carried out by BOLEMA - Boletim de Educação, from 2009 to 2018, it was found that there are 22 works focused on research in relation to Mathematics Education in Youth and Adult Education. Through this survey it was possible to identify the main institutions and researchers that investigate in this area and publish part of their work in the referred electronic library and make a brief analysis of the works linked in this medium of communication, trying to draw a panorama on the studied theme. It also makes a study of the Brazilian public policies employed in order to offer basic education for this type of teaching and also brings a reflection on the pedagogical practices in Youth and Adult Education. Keywords: Mathematics Education, Youth and Adult Education, Studies.

\section{Introdução}

No recanto onde moro é uma linda passarela O carijó canta cedo, bem pertinho da janela Eu levanto quando bate o sininho da capela E lá vou eu pro roçado, tenho Deus de sentinela (Lourenço e Lourival) $^{4}$

\footnotetext{
${ }^{1}$ Universidade Estadual de Mato Grosso do Sul (UEMS), Dourados, anildo.flor@gmail.com.

${ }^{2}$ Universidade Estadual de Mato Grosso do Sul, (UEMS), Universidade Federal da Grande Dourados (UFGD), Dourados, edvonetealencar@ufgd.edu.br

3 Universidade Federal da Grande Dourados (UFGD), Dourados, alessandrafurtado@ufgd.edu.br

${ }^{4}$ Disponível em: https://www.letras.mus.br/lourenco-e-lourival/127299/. Acesso: em 27 março 2019.
} 
Iniciamos nossa reflexão com um trecho da música "Franguinho na panela", interpretada por Lourenço e Lourival, que enuncia um cenário de vida e de trabalho de vida no campo. Infere assim as poucas possibilidades de estudo dadas a esse público e que proporciona que muitos deles utilizem como única alternativa de estudo a Educação de Jovens Adultos (EJA).

Com isso, essa música nos faz refletir sobre como a Educação de Jovens e Adultos possui uma carência de investigações na área e que as poucas existentes devem ser bem compreendidas e estudadas para que se possam incentivar novos rumos nas pesquisas.

Esta investigação utiliza como metodologia o estado do conhecimento que investiga a produção sobre a Educação de Jovens e Adultos publicada no Boletim de Educação Matemática - BOLEMA, nos últimos dez anos (2009 a 2019). O objetivo desta investigação é apresentar um mapeamento de pesquisas realizadas na Área de Educação Matemática voltada para o ensino de Jovens e Adultos.

Assim, em nossas análises, buscamos identificar e descrever como a área se desenvolve no Brasil, bem como quais pesquisadores e instituições vêm pesquisando esta temática, além de investigar quais são os focos temáticos identificados nas pesquisas em EJA e Matemática publicadas em um periódico.

Para isso, fizemos o levantamento em um dos periódicos da área. A escolha pela Bolema deve-se ao alto nível concedido pelo Sistema Qualis-CAPES, que lhe confere o extrato A1 para a área de Avaliação de Ensino e Educação, bem como pelo número considerável de artigos na área específica de Educação Matemática voltada para a EJA nela vinculados. Consideramos, ainda, o fato de ela ser uma das mais antigas revistas do campo, considerada pelo público acadêmico como referência para área de investigação. O Bolema tem como objetivo divulgar o conhecimento científico em Educação Matemática e disciplinas afins. O periódico trabalha com artigos que mostram investigações a respeito de temas, como o aprendizado matemático em sala de aula e o papel da matemática na sociedade.

Para situar o leitor quanto ao referencial teórico sobre o que as pesquisas analisadas se debruçam, apresentamos, na próxima seção, um panorama da área de Educação de Jovens e Adultos bem como a formação dos docentes em relação às práticas pedagógicas. 


\section{EJA: políticas de implementação desenvolvidas no Brasil}

O sistema de construção de políticas voltada a Educação de Jovens e Adultos, no Brasil, é marcado por caminhos e descaminhos por falta de continuidades dos projetos desenvolvidos para atender a esta clientela da educação básica.

De acordo com Haddad e Di Pierro (2000) a ampliação do ensino básico tornou-se uma necessidade devido às diretrizes traçadas para educação nos últimos anos, incluindo a educação de adultos. Com o desenvolvimento industrial, viu-se a necessidade da incorporação da população como mão de obra em grande quantidade. Deste modo, surge a necessidade de implementação da Educação de Jovens e Adultos, destacando-se, em 1947, com a campanha de Educação de Jovens e Adultos.

Esta campanha serviu como um marco inicial nas políticas educacionais para a educação de jovens e adultos. Neste período, foram fundadas várias escolas supletivas, em vários pontos do territoria nacional envolvendo o poder público, os profissionais e muitos voluntários.

A partir de então, muitos debates foram realizados envolvendo a educação, tendo como um dos principais temas a educação e a pobreza, pois o analfabetismo era considerado consequência da pobreza.

Assim, com o objetivo de diminuir a desigualdade social entre a população brasileira, foram desenvolvidos vários programas voltado para educação de jovens e adultos.

Um desses programas foi o MOBRAL, programa idealizado para a educação de jovens e adultos, que teve sua expansão na década de 1970, abrangendo todo o território nacional. Este programa tinha como objetivo erradicar o analfabetismo no Brasil em um período de dez anos. Com uma proposta de desenvolver nestes jovens e adultos técnicas de leitura, escrita e cálculo com a finalidade de integrá-los a sua comunidade, conquistando melhores condições de vida.

Já a Fundação Educar foi fundada, em 1985, substituindo o MOBRAL. No entanto, a referida Fundação não trabalhava diretamente com a educação de jovens e adultos, mas apoiava financeiramente e oferecia suporte técnico por meio de convênios firmados com instituições públicas, civis e empresas.

Com a promulgação da Constituição Federal de 1988, a educação ganha novos caminhos, sendo garantida como direito de todos os cidadãos. (BRASIL, 1988). O artigo 208 da Constituição 
assegura: “I - educação básica obrigatória e gratuita dos 4 (quatro) aos 17 (dezessete) anos de idade, assegurada inclusive sua oferta gratuita para todos os que a ela não tiveram acesso na idade própria”. O artigo, além de garantir a educação básica gratuita e obrigatória para crianças e jovens dos 4 aos 17 anos de idade, também assegura o direito aos jovens e adultos que não tiveram acesso na idade própria.

Segundo a Lei de Diretrizes e Bases da Educação Nacional (LDB, 9.394), a escolarização de jovens e adultos ganha novos rumos, que determina o oferecimento de cursos e exames, os quais oportunizam condições educacionais adequadas às condições de vida dos alunos jovens e adultos. De acordo com o Artigo 37 da LDB: (BRASIL, 1996)

$\S 1$ O Os sistemas de ensino assegurarão gratuitamente aos jovens e aos adultos, que não puderam efetuar os estudos na idade regular, oportunidades educacionais apropriadas, consideradas as características do alunado, seus interesses, condições de vida e de trabalho, mediante cursos e exames.

No entanto, apesar da garantia do oferecimento desta modalidade de ensino, o seu financiamento não era garantido pelo Fundo de Manutenção e Desenvolvimento do Ensino Fundamental e de Valorização do Magistério (FUNDEF- consubstanciado pela Lei 9424/96) fato este que levou estados e municípios a não investirem na EJA.

A partir da LDB 9.394, de 1996, surgiram programas voltados para a alfabetização de jovens e adultos entre os quais destacamos.

O Programa Alfabetização Solidária (PAS), desenvolvido por uma entidade não governamental, que oferecia a educação de jovens e adultos por meio de convênios com as universidades públicas e privadas. O PAS recebia os recursos do MEC e repassava às entidades conveniadas.

Outro programa direcionada à EJA, criado em 1998, foi o Programa Nacional de Educação na Reforma Agrária (PRONERA), executado através de convênios com estados, municípios, universidades e organização da sociedade civil.

Com o Plano Nacional de Educação, em 2001, foram traçadas várias metas relacionada à EJA. Neste período, surgiu também o Programa Recomeço, que disponibilizava aporte financeiro aos municípios e estados das regiões Norte e Nordeste, estados integrantes do Projeto Alvorada. 
Em 2003, com a troca de gestão no Governo Federal, o MEC assumiu a responsabilidade com a alfabetização de adultos, lançando o Programa Brasil Alfabetizado (PBA). Também foi criada a Secretaria Extraordinária de Erradicação do Alfabetismo (SEEA), destinando recursos para o Programa Brasil Alfabetizado (PBA), a fim de enfrentar o analfabetismo em todo o país.

A Secretaria de Educação Continuada, Alfabetização e Diversidade (SECAD) absorveu a Secretaria Especial de Erradicação do Analfabetismo (SEEA) e passou a comandar e a gerir as políticas do PBA; dessa forma, administrando todas as políticas voltadas para a EJA.

Com o objetivo de ampliar as vagas no ano de 2005 , foram traçadas novas ações para o avanço da EJA. O Governo Federal, por meio do Programa de Apoio aos Sistemas de Ensino para Atendimento da Educação de Jovens e Adultos, passou a repassar verbas para o financiamento da EJA nos estados, no Distrito Federal e nos municípios.

No entanto, é importante destacar que o grande avanço na EJA efetivou-se com a Emenda Constitucional no 53, de 19 de dezembro de 2006. Essa Emenda constituiu o Fundo de Manutenção e Desenvolvimento da Educação Básica e de Valorização dos Profissionais da Educação (FUNDEB), que possibilitou o financiamento desta modalidade de ensino. (BORGES; JESUS, 2013). Assim, oportunizou a criação e a manutenção de vários projetos e programas voltados para este público da educação básica, dos quais destacamos alguns.

1) Mova Brasil: De acordo com o Instituto Paulo Freire ${ }^{5}$, este Projeto foi criado pelo educador Paulo Freire e passou a ter parceria com a Petrobras, em 2013.

2) Programa Alfabetização Multimeios ${ }^{6}$ : em sua abrangência estadual, atendeu a jovens, adultos e idosos do Estado do Maranhão, entre 2008 e 2009, alfabetizando por meio de uma proposta metodológica inovadora, resultado de uma parceria entre o Instituto Paulo Freire e a Universidade Virtual do Estado do Maranhão (UNIVIMA).

3) Programa Brasil Alfabetizado (PBA): implantado em 2003 para promover a superação de analfabetismo entre os jovens a partir dos 15 anos de idade.

4) PROJOVEM: tem por finalidade elevar a escolaridade entre jovens de 18 a 29 anos, que

\footnotetext{
${ }^{5}$ Programa Mova Brasil. Disponível em: http://www.paulofreire.org/mova-brasil. Acesso em: 23 fev. 2019.

${ }^{6}$ Programa Alfabetização Multimeios. Disponível em: http://www.paulofreire.org/programas-e-projetos/educacaode-adultos/ programa-alfabetização-multimeios. Acesso em: 23 fev. 2019.
} 
não tenham concluído o Ensino Fundamental, proporcionando a conclusão desta etapa do ensino por meio da modalidade de Educação de Jovens Adultos integrada à qualificação profissional no período de 2008 a 2010.

5) Coleção Cadernos de EJA: objetivava organizar os componentes e conteúdos em torno de eixos temáticos, para alfabetização até o final do $2 \stackrel{0}{\circ}$ segmento.

6) Programa Nacional do Livro Didático para Alfabetização de Jovens e Adultos (PNLDEJA): objetivava disponibilizar livros didáticos aos alfabetizados e estudantes jovens, adultos e idosos das entidades parceiras do Programa Brasil Alfabetizado.

7) Programa Alfabetização em Prisões: tem como propósito dar apoio técnico e financeiro para a implementação da Educação de Jovens e Adultos no sistema penitenciário.

8) Medalha Paulo Freire: tem por objeto identificar, reconhecer e estimular as experiências educacionais no campo da educação de jovens e adultos.

9) PROEJA: Programa Nacional de Integração da Educação Profissional com a Educação Básica na Modalidade de Jovens e Adultos.

10) Programa Alfabetização Solidária: tem por finalidade combater o analfabetismo existente em muitos municípios do Brasil ${ }^{7}$.

Todos estes programas, além de estarem voltados à alfabetização dos Jovens e Adultos em Língua Portuguesa, trabalharam com a apropriação da matemática, pois é um componente da grade curricular da EJA, constituindo um elemento de grande importância no desenvolvimento do caráter sócio educacional.

O Plano Nacional de Educação, para o período de 2014 a 2024, contempla na EJA as metas 9 e 10, tendo como propósito a erradicação do analfabetismo absoluto e, ainda, propõe a integração da educação profissional à educação básica.

\section{Docência na EJA: formação e práticas metodológicas}

Ao falarmos em práticas pedagógicas na EJA, é necessário fazermos uma pequena análise das formações que os professores licenciados receberam em sua formação de licenciatura.

\footnotetext{
${ }^{7}$ Disponível em: http://portal.mec.gov.br/component/tags/tag/32737-eja. Acesso em: 10 fev.2019.
} 
Assim, é importante destacar que esta modalidade tem duas funções: reparação e emancipação.

Quanto à reparação, o Parecer CNE/CEB no. 11/2000 afirma que:

Nesta ordem de raciocínio, a Educação de Jovens e Adultos (EJA) representa uma dívida social não reparada para com os que não tiveram acesso a e nem domínio da escrita e leitura como bens sociais, na escola ou fora dela, e tenham sido a força de trabalho empregada na constituição de riquezas e na elevação de obras públicas. Ser privado deste acesso é, de fato, a perda de um instrumento imprescindível para uma presença significativa na convivência social contemporânea (BRASIL, 2000, p.5).

Nesta perspectiva, fica evidenciada que umas das grandes missões da Educação de Jovens e Adultos é reparar os danos que um estudante teve por não ter a oportunidade de frequentar uma escola no período correto de escolarização.

Em relação à emancipação, pretende-se oferecer a oportunidade a esses jovens e adultos de participarem da sociedade em que vivem, sendo capazes de defenderem seus pontos de vistas com fundamentação, colaborando para a construção do meio em que vive.

O fato é que, até alguns anos atrás, os cursos de licenciatura não ofereciam em sua matriz curricular que abrangia esta modalidade de ensino. Por este motivo, muitos professores, que assumiam a responsabilidade de ministrar aulas na EJA, simplesmente reproduziam as metodologias utilzadas para trabalhar com crianças.

Muitos professores que integram os programas de educação de jovens e adultos têm ou já tiveram experiência com o ensino regular infantil e, baseados nessa experiência, colocam-se questões. Os métodos e os conteúdos da educação infantil servem para os jovens e adultos? Quais as especificadas dessa faixa etária? Procurando responder a essas indagações e aos desafios apresentados por seus alunos, vão tentando adaptações, mudanças de postura, de estratégias e de conteúdo (BRASIL, 2001, p.13).

No entanto, o que observamos, muitas vezes, é, que por falta de formação adequada, alguns professores acabam sem motivação e cansados de estratégias que não dão certo. Isto acaba refletindo diretamente na sala de aula, levando à desmotivação dos alunos e, geralmente, à desistência. 
Outro ponto a destacar é a diversidade da clientela atendida na EJA, o que também dificulta o professor em encontrar um meio que consiga abranger a turma como um todo. Além disso, é necessário considerar as formas de organização dos programas. Com relação a esta diversidade, Brasil (2001, p.14) afirma que: "A educação de jovens e adultos correspondente a este nível de ensino caracteriza-se não pela diversidade do público que atende e dos contextos em que se realiza, como pela variedade dos modelos de organização dos programas, mais ou menos formais, mais ou menos extensivos".

Diante do exposto, o professor, que tem como propósito trabalhar com a EJA, deve ter a consciência que esta modalidade de ensino exige uma proposta metodológica diferenciada das desenvolvidas nas turmas do ensino regular, tendo condições para definir estratégias para cada caso específico que seja eficaz para o processo de aprendizagem do estudante.

Desta forma, Brasil (2001, p.52) afirma que:

Com maior razão, pode-se dizer que o preparo de um docente voltado para a EJA deve incluir, além das exigências formativas para todo e qualquer professor, aquelas relativas à complexidade diferencial desta modalidade de ensino. Assim esse profissional do magistério deve estar preparado para interagir empaticamente com esta parcela de estudantes e de estabelecer o exercício do diálogo. Jamais um professor aligeirado ou motivado apenas pela boa vontade ou por um voluntariado idealista e sim um docente que se nutra do geral e também das especificidades que a habilitação como formação sistemática requer.

Podemos observar que a Educação de Jovens e Adultos é uma modalidade que exige do professor habilidade para trabalhar com este público. E a falta de formação direcionada para professores da EJA é um fator negativo da qualidade de ensino ofertada a estudantes jovens e adultos.

De acordo com o Marco de Ação de Belém (UNESCO, 2010, p.21).

A falta de oportunidades de profissionalização e de formação para educadores tem um impacto negativo sobre a qualidade da oferta de aprendizagem e educação de adultos, assim como o empobrecimento do ambiente de aprendizagem, no que diz respeito a equipamentos, materiais e currículos. Raramente são realizadas avaliações de necessidades e pesquisas sistemáticas, no processo de planejamento, para determinar conteúdos, pedagogia, modo de provisão e infraestrutura de apoio adequadas. 
A falta de uma formação que dê conta dos aspectos singulares dessa Modalidade de Ensino, tem se revelado como uma grande problematização, considerando a clientela da EJA diferencia-se dos alunos da educação regular por se tratar de pessoas que já possuem uma grande vivência em sociedade.

Capucho $(2012$, p.65) nos mostra que "a problematização da formação de professores (as) para atuação na Educação de Jovens e Adultos tem revelado não terem os(as) profissionais dessa modalidade, em sua maioria, habilitação específica para tal". A falta de formação capaz de dar conta destes aspectos singulares, tem revelado dentro das salas de aula da EJA professores utilizando os mesmos métodos utilizados nas turmas do ensino regular.

Ainda é importante ressaltar que, de acordo com Capucho (2012), a Educação de Jovens e Adultos é oferecida em diversos lugares, que, muitas vezes, não oferecem condições para o desenvolvimento de uma metodologia que vá ao encontro do que é esperado por estes alunos.

Dentre os fatores específicos da EJA, destacamos a grande diversidade de contextos em que se desenvolve a prática pedagógica e a pluralidade de seus sujeitos.

Além disso, devemos pensar que as Universidade não avançaram na perspectiva de formar professores para atuarem na Educação de Jovens e Adultos. Em uma entrevista à Univesp TV, a professora e pesquisadora Silmara Campos, da Unicamp, que desenvolve pesquisa nesta área, apontou a grande problemática dos cursos de licenciatura nesta área. (UNIVESP TV, 2014). Os cursos de licenciatura, em sua grande maioria, têm o foco no desenvolvimento da criança e não no adulto. Ainda afirma que alguns cursos oferecem disciplinas voltado para a EJA, mas devido à pouca carga horária não se estuda o desenvolvimento do adulto nem os métodos para trabalhar com esses alunos. Esse fato ocorre pela pouca carga horária disponibilizada para que haja um debate sobre a temática abordada.

Assim, fica evidenciado que a formação inicial dos professores em relação as práticas pedagógicas as vezes não contempla a realidade da EJA. Devido ao pouco contato com o tema durante a sua formação na licenciatura, a:

[...] maioria dos(as) professores(as) atuante nos sistemas municipais, estaduais e também no sistema prisional em turmas de EJA nunca recebeu formação especifica para a função que exerce; quando o foco é direcionado 
para os(as) educadores(as) atuantes em Programas de Alfabetização, a situação se torna ainda mais complexa, pois impera o quadro de leigos, que recebem uma formação aligeirada e insuficiente para o desafio que vivenciam nos espaços/tempos pedagógicos em que atuam (CAPUCHO, 2012, p.66).

De fato, os alfabetizadores dos programas de alfabetização de adultos, geralmente, são pessoas que não possuem uma formação para a docência nem em nivel médio. Estas pessoas são submetidas a cursos de formação de poucas horas e entram nas salas de aula com os materiais prontos sem considerar o meio em que estes alunos vivem.

Neste cenário, fica evidenciada a necessidade de alguns enfrentamentos com relação às práticas pedagógicas na EJA. Entre os temas a serem debatidos, destacamos: a) formação inicial para os docentes; b) fortalecimento do papel dos pegagogos atuantes na Educação de Jovens e Adultos que não tiveram formação adequada para trabalhar com este público; c) necessidade de complementação de carga horária de professor; d) desmitificação de que com as turmas da EJA é mais fácil trabalhar; e) exigência maior quanto à aprendizagem.

Apesar de muitas barreiras, há profissionais que optaram por desenvolver um trabalho voltado para a EJA. Com isso, procuram integrar estes alunos ao sistema de ensino, considerando sua vivênvia e procurando aplicar uma metodologia diferenciada que favoreça a aprendizagem destes educandos.

\section{Caminhos metodológicos}

Esta investigação é do tipo estado do conhecimento, uma das modalidades de revisão bibliográfica referenciada por Romanovisky e Ens (2006, p.40), os quais consideram este tipo de investigação como: "O estudo que aborda apenas um setor das publicações sobre o tema estudado".

A busca foi realizada nos sites da revista e da The Scientific Electronic Library Online SciELO. Esta se justifca pelo fato dos sites das revistas possuirem artigos até 2011 e após a indexação na base SciELO estes foram disponibilizados na referida biblioteca eletrônica. Para realizar a procura, utilizamos a palavra-chave: Educação de Jovens e Adultos. No primeiro levantamento, obtivemos 29 artigos. 
Inicialmente, fizemos a leitura prévia dos títulos e dos resumos para identificarmos se tratavam da temática. Do total de 29, 22 artigos referenciavam-se realmente ao público da Educação De Jovens E Adultos - EJA. Com isso, os artigos selecionados e organizado no Quadro 1.

Quadro 1- Artigos analisados

\begin{tabular}{|c|c|c|}
\hline Ano & Título & Autores \\
\hline 2005 & $\begin{array}{l}\text { O Tempo Vivido Pelo Alfabetizando Adulto } \\
\text { nas Aulas de Matemática. }\end{array}$ & Barreto; Bicudo. \\
\hline 2008 & $\begin{array}{l}\text { A Etnomatemática no contexto do ensino } \\
\text { inclusivo: Possibilidades e Desafios. }\end{array}$ & Donda Rodrigues. \\
\hline 2008 & $\begin{array}{l}\text { As "Ticas" de "Matema" de Cegos Sob o Viés } \\
\text { Institucional: da integração à inclusão. }\end{array}$ & $\begin{array}{l}\text { Casagrande de Oliveira; } \\
\text { Scandiuzzi. }\end{array}$ \\
\hline 2009 & $\begin{array}{l}\text { Práticas Sociais de Localização e } \\
\text { Mapeamento: uma discussão curricular } \\
\text { sobre o conceito de escala. }\end{array}$ & de Lima; Monteiro. \\
\hline 2010 & $\begin{array}{l}\text { Entrelaçamentos e Dispersões de } \\
\text { Enunciados no Discurso da Educação } \\
\text { Matemática Escolar: um } \\
\text { estudo sobre a importância de trazer a } \\
\text { "realidade" do aluno para as aulas de } \\
\text { Matemática. }\end{array}$ & Knijnik, Glavam Duarte. \\
\hline 2011 & $\begin{array}{l}\text { A Aprendizagem de Matemática por Alunos } \\
\text { Adolescentes na Modalidade Educação } \\
\text { de Jovens e Adultos: analisando as } \\
\text { dificuldades na resolução de problemas de } \\
\text { estrutura aditiva. }\end{array}$ & Queiroz; Lins. \\
\hline 2011 & $\begin{array}{l}\text { Itinerários do Grupo de Estudo e Pesquisa } \\
\text { em } \\
\text { Etnomatemática e sua Relação com a } \\
\text { Educação } \\
\text { Matemática. }\end{array}$ & Scandiuzzi; Lübeck. \\
\hline 2011 & $\begin{array}{l}\text { O Letramento Presente na Construção de } \\
\text { Tabelas por Alunos da Educação } \\
\text { de Jovens e Adultos. }\end{array}$ & $\begin{array}{l}\text { Conti; Lucchesi } \\
\text { Carvalho. }\end{array}$ \\
\hline 2012 & $\begin{array}{l}\text { Reseña de "A Etnomatemática no Contexto } \\
\text { do Ensino Inclusivo" }\end{array}$ & Cruz dos Santos. \\
\hline
\end{tabular}




\begin{tabular}{|c|c|c|}
\hline Ano & Título & Autores \\
\hline 2012 & Saúde e Números: uma parceria de sucesso. & $\begin{array}{l}\text { Reis de Miranda; Scheid } \\
\text { Gazire }\end{array}$ \\
\hline 2013 & $\begin{array}{l}\text { Interdisciplinaridade no PROEJA: uma } \\
\text { proposta possivel no caderno temático } \\
\text { Saúde e Números. }\end{array}$ & $\begin{array}{l}\text { Reis de Miranda; Scheid } \\
\text { Gazire. }\end{array}$ \\
\hline 2013 & $\begin{array}{l}\text { Jovens e Adultos Construindo e } \\
\text { Interpretando Gráficos. }\end{array}$ & Lima; Selva. \\
\hline 2014 & $\begin{array}{l}\text { Gestão do Currículo de Matemática sob } \\
\text { Diferentes Profissionalidades. }\end{array}$ & Crecci; Fiorentini. \\
\hline 2014 & $\begin{array}{l}\text { Livros Didáticos e Apostilas: o currículo de } \\
\text { matemática e a } \\
\text { dualidade do ensino médio. }\end{array}$ & Fonseca; Vilela. \\
\hline 2014 & $\begin{array}{l}\text { O Currículo de Matemática em revista: um } \\
\text { editorial. }\end{array}$ & $\begin{array}{l}\text { Pires; Godoy; Silva; } \\
\text { Santos. }\end{array}$ \\
\hline 2014 & $\begin{array}{l}\text { Pesquisas e Documentos Curriculares no } \\
\text { Âmbito da Educação Matemática de Jovens e } \\
\text { Adultos. }\end{array}$ & Januário; Freitas; Lima. \\
\hline 2014 & $\begin{array}{l}\text { Práticas Laborais nas Salas de Aula de } \\
\text { Matemática da EJA: perspectivas e tensões } \\
\text { nas concepções de aprendizagem. }\end{array}$ & $\begin{array}{l}\text { Schneider; Ferreira Reis } \\
\text { Fonseca. }\end{array}$ \\
\hline 2015 & $\begin{array}{l}\text { Ensino de Área de Figuras Geométricas } \\
\text { Planas no Currículo de Matemática do } \\
\text { Projovem Urbano. }\end{array}$ & Carvalho; Bellemain. \\
\hline 2015 & $\begin{array}{l}\text { Estudos em Raciocínio Combinatório: } \\
\text { investigações e práticas de ensino na } \\
\text { Educação Básica. }\end{array}$ & $\begin{array}{l}\text { de Souza Rosa Borba; de } \\
\text { Arimatéa Rocha; Azevedo. }\end{array}$ \\
\hline 2015 & $\begin{array}{l}\text { Práticas Efetivas em Educação Matemática } \\
\text { no contexto de um banco comunitário. }\end{array}$ & $\begin{array}{l}\text { Geromel Meneghetti; } \\
\text { Zacheo Barrofaldi. }\end{array}$ \\
\hline 2015 & $\begin{array}{l}\text { Reflexões sobre Relações entre Currículo, } \\
\text { Avaliação e Formação de Professores na } \\
\text { Área de Educação Matemática. }\end{array}$ & Pires. \\
\hline 2016 & $\begin{array}{l}\text { A Interdisciplinaridade no Ensino É Possivel? } \\
\text { Prós e contras na perspectiva de professores } \\
\text { de Matemática. }\end{array}$ & Ocampo; Santos; Folmer. \\
\hline
\end{tabular}

Fonte: Elaborado pelos pesquisadores com base nos dados coletados na Revista BOLEMA (2019).

Após o levantamento e a leitura do título e do resumo, realizamos a leitura na íntegra dos artigos, considerando os seguintes aspectos: 1) origens e quantitativo de autorias dos trabalhos selecionados; 2) temáticas de aprofundamento; 3) metodologias empregadas; 4) matemática abordada nas investigações. 


\section{Sobre as origens e as autorias dos trabalhos analisados}

Em relação à origem dos trabalhos, destacamos a autoria dos estudos, onde $18,18 \%$ dos artigos foram escritos por um autor. Enquanto que os trabalhos produzidos coletivamente, aqueles que têm mais de um autor somam $81,82 \%$ dos artigos analisados. Desses $63,63 \%$ são produzidos por dois autores, 13,63\% produzidos por três autores e 4,56\% produzidos por quatro autores (Tabela 1). Ainda encontramos alguns trabalhos oriundos de dissertações e teses, este tem a assinatura do autor e seu orientador.

Tabela 1 - Número de autores por publicações

\begin{tabular}{ccc}
\hline $\mathrm{N}^{0}$ de Autores & Freq. & Freq. \\
\hline 1 & 4 & $18,18 \%$ \\
2 & 14 & $63,63 \%$ \\
3 & 3 & $13,63 \%$ \\
4 & 1 & $4,56 \%$ \\
\hline Total & 22 & $100,00 \%$ \\
\hline
\end{tabular}

Fonte: Elaborado pelos pesquisadores com base nos dados coletados (2019).

Em relação ao número de trabalhos aprovados, neste periódico se destaca os artigos oriundos da Universidade Estadual Paulista Júlio de Mesquita Filho (UNESP), em Rio Claro, com 18 trabalhos publicados; a Universidade Federal de Pernambuco (UFPE) com dois trabalhos, e a Pontifícia Universidade Católica de São Paulo (PUC-SP) também com dois trabalhos publicados.

\section{Temáticas de aprofundamento}

Ao analisar as temáticas de aprofundamento utilizadas pelos pesquisadores em suas investigações, ressaltamos o estudo referente ao currículo com cinco trabalhos e a sequência didática que estava presente em quatro trabalhos pesquisados. O quadro a seguir demonstra as demais temáticas: 
Quadro 2 - Distribuição da temática de aprofundamento

\begin{tabular}{|c|c|c|}
\hline Temáticas de aprofundamento & $\begin{array}{l}\text { No de } \\
\text { trabalhos }\end{array}$ & Autores \\
\hline \multirow{5}{*}{$\begin{array}{l}\text { Estudos sobre Currículos da } \\
\text { EJA }\end{array}$} & \multirow[t]{5}{*}{05} & CARVALHO; BELLEMAIN (2015). \\
\hline & & CRECCI; FIORENTINI (2014). \\
\hline & & FONSECA; VILELA (2014). \\
\hline & & PIRES; GODOY; SILVA; SANTOS (2014). \\
\hline & & JANUARIO; FREITAS; LIMA (2014). \\
\hline \multirow[t]{4}{*}{ Sequência Didática } & \multirow[t]{4}{*}{04} & QUEIROZ; LINS (2011). \\
\hline & & LIMA; SELVA (2013). \\
\hline & & CONTI; LUCCHESI DE CARVALHO (2011). \\
\hline & & $\begin{array}{l}\text { REIS DE MIRANDA; SCHEID GAZIRE } \\
\text { (2012). }\end{array}$ \\
\hline \multirow{3}{*}{$\begin{array}{l}\text { Educação matemática e } \\
\text { inclusão }\end{array}$} & \multirow[t]{3}{*}{03} & DONDA RODRIGUES. (2008). \\
\hline & & $\begin{array}{l}\text { CASAGRANDE DE OLIVEIRA; SCANDIUZZI. } \\
(2008) \text {. }\end{array}$ \\
\hline & & CRUZ DOS SANTOS (2012). \\
\hline Recursos Didáticos & 01 & $\begin{array}{l}\text { DE SOUZA ROSA BORBA; DE ARIMATÉA } \\
\text { ROCHA; AZEVEDO. (2015). }\end{array}$ \\
\hline \multirow{3}{*}{$\begin{array}{l}\text { A abordagem interdisciplinar } \\
\text { no ensino }\end{array}$} & \multirow[t]{3}{*}{03} & OCAMPO; SANTOS; FOLMER (2016). \\
\hline & & KNIJNIK; GLAVAM DUARTE (2010). \\
\hline & & $\begin{array}{l}\text { REIS DE MIRANDA; SCHEID GAZIRE } \\
(2013) \text {. }\end{array}$ \\
\hline \multirow[t]{2}{*}{ Pesquisa em Etnomatemática } & \multirow[t]{2}{*}{02} & SCANDIUZZI; LÜBECK (2011). \\
\hline & & DE LIMA; MONTEIRO (2009). \\
\hline $\begin{array}{l}\text { A escola e educação de jovens } \\
\text { e adultos }\end{array}$ & 01 & BARRETO; BICUDO (2005). \\
\hline $\begin{array}{l}\text { Currículo, avaliação e } \\
\text { formação de professores }\end{array}$ & 01 & PIRES (2015). \\
\hline Jogos e prática laboral & 01 & $\begin{array}{l}\text { SCHNEIDER; FERREIRA REIS FONSECA } \\
(2014) \text {. }\end{array}$ \\
\hline $\begin{array}{l}\text { Matemática e Economia } \\
\text { Solidária }\end{array}$ & 01 & $\begin{array}{l}\text { GEROMEL MENEGHETTI; } \\
\text { BARROFALDI (2015). }\end{array}$ \\
\hline
\end{tabular}

Fonte: Elaborado pelos pesquisadores com base nos dados coletados (2019).

O quadro acima nos mostra que, quando se trata de Educação de Jovens e Adultos, há uma grande preocupação em relação ao currículo e aos materiais didáticos utilizados para trabalhar com esta clientela. Fato este que revela que há pesquisadores que tem realizado estudos no campo do currículo, procurando oferecer aos educadores desta modalidade de ensino materiais alternativo voltado para o ensino e aprendizagem de estudantes jovens e adultos. Percebemos também uma diversidade quanto aos temas pesquisados, mostrando um grande interesse dos pesquisadores em buscar alternativas para oferecer a estes estudantes um 
ensino voltado para sua idade e realidades.

Nesse direcionamento, é importante compreender que as pesquisas procuram analisar aspectos voltados à educação, como um espaço de gestão democrática, os quais devem aproximarem-se o máximo possível do contexto cultural e da condição socioeconômica deste estudante, compreendendo a organização da sociedade atual

\section{Metodologias e métodos empregados nas publicações analisadas}

Quanto às metodologias e métodos de pesquisa utilizados nas investigações publicadas, percebemos grande variedade, com destaque para os textos que fazem uma discussão e reflexão de um material coletado a partir da aplicação de uma determinada atividade a um grupo de alunos e a utilização de "Estudo de Caso", ambos encontrados em 20 trabalhos dos 22 analisados. Outras evidências foram: aplicação de testes, análise de conteúdo, pesquisa bibliográfica, pesquisa participante ou somente denominada de pesquisa qualitativa. Essas temáticas denotam que o pesquisador da área de Educação Matemática para Jovens e Adultos, ora estudada, valemse prioritariamente de métodos qualitativos de pesquisas, como é possível verificar na Tabela 2:

Tabela 2 - Distribuição dos métodos de pesquisas

\begin{tabular}{cll}
\hline Número & Metodologia & $\mathrm{N}^{\circ}$ de Trabalhos \\
\hline 01 & Discussão e reflexão & 05 \\
02 & Estudo de caso & 04 \\
03 & Análise de conteúdos & 03 \\
04 & Análise interpretativa & 05 \\
05 & Entrevistas e questionários & 03 \\
06 & Análise discursiva & 02 \\
\hline Total & & 22 \\
\hline
\end{tabular}

Fonte: Elaborado pelos pesquisadores com base nos dados coletados (2019)

Assim, ao delinearmos os desafios e as perspectivas para EJA, percebemos que a discussão e a reflexão sobre os estudos realizados mostram a possibilidade de se ter uma educação voltada para esta modalidade de ensino, em que a Educação de Jovens e Adultos possa estar integrada ao processo educativo desenvolvendo-se em múltiplas dimensões, como a do 
conhecimento, das práticas sociais, do trabalho e da construção da cidadania. Assim, mostra-nos que a EJA pode ultrapassar o âmbito das ações desenvolvidas nas escolas, abrangendo outros espaços, como, exemplo, associações e locais de trabalho, adaptando-se, desta forma, à realidade deste estudante trabalhador.

\section{A Matemática abordada pelas pesquisas}

Já em relação ao tema Educação de Jovens e Adultos e Matemática, abordado pelas investigações aqui analisadas, percebemos que, em geral, os trabalhos tratam de os conceitos da matemática; a educação inclusiva; a formação de professores; o ensino e aprendizagem e a realidade do estudante; o currículo de matemática do Projovem Urbano ${ }^{8}$; a resolução de problemas; o conceito de escola; a prática matemática da EJA; a educação matemática comunitária; o sistema de numeração decimal;, as tabelas na EJA; a etnomatemática e a relação com a educação matemática; o gênero e a educação matemática; a alfabetização matemática de adultos; a aprendizagem matemática na modalidade EJA, a interdisciplinaridade no ensino e aprendizagem de matemática, e o currículo na EJA.

O quadro a seguir mostra de um modo geral o foco temático, o subfoco e o número de autores que realizaram pesquisas envolvendo diversos tema na área da educação de jovens e adultos e o ensino da matemática.

Quadro 3 - Foco temático e subfoco

\begin{tabular}{|c|c|c|c|}
\hline FOCO TEMÁTICO & SUBFOCO & N. & AUTORES \\
\hline \multirow{4}{*}{$\begin{array}{l}\text { Ensino e } \\
\text { Aprendizagem }\end{array}$} & $\begin{array}{l}\text { Dificuldades no ingresso } \\
\text { do mercado de trabalho }\end{array}$ & 02 & QUEIROZ; LINS (2011). \\
\hline & Raciocínio combinatório & 03 & $\begin{array}{l}\text { DE SOUZA ROSA BORBA; DE } \\
\text { ARIMATÉA ROCHA; } \\
\text { AZEVEDO. (2015). }\end{array}$ \\
\hline & $\begin{array}{l}\text { Interpretação } \\
\text { construção de gráficos }\end{array}$ & 02 & LIMA; SELVA (2013). \\
\hline & Letramento estatístico & 02 & $\begin{array}{l}\text { CONTI; LUCCHESI DE } \\
\text { CARVALHO (2011). }\end{array}$ \\
\hline
\end{tabular}

\footnotetext{
${ }^{8}$ O Programa Nacional de Inclusão de Jovens - Projovem Urbano é um programa educacional destinado a jovens entre 18 e 29 anos, residentes em áreas urbanas. (MEC)
}

Periódico Horizontes - USF - Itatiba, SP - Brasil - 


\begin{tabular}{|c|c|c|c|}
\hline FOCO TEMÁTICO & SUBFOCO & N. & AUTORES \\
\hline \multirow{3}{*}{$\begin{array}{l}\text { Educação } \\
\text { Inclusiva }\end{array}$} & \multirow[t]{2}{*}{ Etnomatemática } & 01 & $\begin{array}{l}\text { DONDA RODRIGUES. } \\
(2008) .\end{array}$ \\
\hline & & 02 & $\begin{array}{l}\text { CASA GRANDE DE } \\
\text { OLIVEIRA; SCANDIUZZI. } \\
(2008) .\end{array}$ \\
\hline & $\begin{array}{l}\text { A Etnomatemática no } \\
\text { contexto do ensino } \\
\text { inclusivo }\end{array}$ & 01 & CRUZ DOS SANTOS (2012). \\
\hline \multirow{6}{*}{$\begin{array}{l}\text { Currículo de } \\
\text { Matemática }\end{array}$} & $\begin{array}{ll}\text { Figuras } & \text { geométricas } \\
\text { planas } & \end{array}$ & 02 & $\begin{array}{l}\text { CARVALHO; BELLEMAIN } \\
\text { (2015). }\end{array}$ \\
\hline & Material didático & 02 & FIORENTINI (2014). \\
\hline & $\begin{array}{l}\text { Apostilas e livros didáticos } \\
\text { de matemática do ensino } \\
\text { médio }\end{array}$ & 02 & FONSECA; VILELA (2014). \\
\hline & Grupo de pesquisas & 04 & $\begin{array}{l}\text { PIRES; GODOY; SILVA; } \\
\text { SANTOS (2014). }\end{array}$ \\
\hline & Pesquisas sobre EJA & 03 & $\begin{array}{l}\text { JANUARIO; FREITAS; LIMA } \\
\text { (2014). }\end{array}$ \\
\hline & $\begin{array}{l}\text { Saberes relacionados a } \\
\text { procedimentos de } \\
\text { desenhos de mapas }\end{array}$ & 02 & $\begin{array}{l}\text { DE LIMA; MONTEIRO } \\
(2009) .\end{array}$ \\
\hline \multirow[b]{2}{*}{$\begin{array}{l}\text { Educação } \\
\text { Matemática } \\
\text { Escolar }\end{array}$} & $\begin{array}{l}\text { Dar significado aos } \\
\text { conteúdos matemáticos }\end{array}$ & 02 & $\begin{array}{l}\text { KNIJNIK; GLAVAM DUARTE } \\
(2010) \text {. }\end{array}$ \\
\hline & $\begin{array}{l}\text { Currículo, avaliação e } \\
\text { formação de professores } \\
\text { na área de educação } \\
\text { matemática }\end{array}$ & 01 & PIRES (2015). \\
\hline \multirow{2}{*}{$\begin{array}{l}\text { Interdisciplinarid } \\
\text { ade }\end{array}$} & Material didático & 02 & $\begin{array}{l}\text { REIS DE MIRANDA; SCHEID } \\
\text { GAZIRE (2012). }\end{array}$ \\
\hline & Formação de professores & 03 & $\begin{array}{l}\text { OCAMPO; SANTOS; } \\
\text { FOLMER (2016). }\end{array}$ \\
\hline $\begin{array}{l}\text { Educação } \\
\text { Etnomatemática }\end{array}$ & Formação & 02 & $\begin{array}{l}\text { SCANDIUZZI; LÜBECK } \\
\text { (2011). }\end{array}$ \\
\hline $\begin{array}{l}\text { A escola e a } \\
\text { Educação de } \\
\text { Jovens e Adultos }\end{array}$ & $\begin{array}{l}\text { Relação dos sujeitos com a } \\
\text { Matemática escolarizada }\end{array}$ & 02 & BARRETO; BICUDO (2005). \\
\hline $\begin{array}{l}\text { Economia } \\
\text { Solidária }\end{array}$ & $\begin{array}{ll}\text { Gestão financeira e } \\
\text { logística }\end{array}$ & 02 & $\begin{array}{l}\text { GEROMEL MENEGHETTI; } \\
\text { ZACHEO BARROFALDI } \\
\text { (2015). }\end{array}$ \\
\hline Práticas Laborais & $\begin{array}{l}\text { Jogos que mobilizam } \\
\text { práticas laborais }\end{array}$ & 02 & $\begin{array}{l}\text { SCHNEIDER; FERREIRA REIS } \\
\text { FONSECA (2014). }\end{array}$ \\
\hline $\begin{array}{l}\text { Educação } \\
\text { Profissional e } \\
\text { Tecnológica }\end{array}$ & $\begin{array}{l}\text { Material didático; Agente } \\
\text { comunitário de saúde }\end{array}$ & 02 & $\begin{array}{l}\text { REIS DE MIRANDA; SCHEID } \\
\text { GAZIRE (2013). }\end{array}$ \\
\hline
\end{tabular}

Fonte: Elaborado pelos pesquisadores com base nos dados coletados (2019) 
A abrangência e a reflexão a respeito do campo do Ensino Matemático apresentado no quadro três, compõem diferentes focos temáticos, nos quais também merecem destaque os subfocos pautados nas reflexões a respeito do processo de ensino-aprendizagem na Educação de Jovens e Adultos e do conhecimento dos professores relacionado a esta etapa de ensino. Neste foco temático, as análises procuram aproximar características dos docentes que ensinam a Matemática na Educação de Jovens e Adultos, constatando a respeito de como eles articulam informações sobre o conteúdo e a didática, além de procurarem apresentar estudos sobre características sociodemográficas das práticas educacionais.

\section{Algumas considerações}

Esta pesquisa, do tipo Estado do Conhecimento, realizou o levantamento de investigações sobre a Educação Matemática para Jovens e Adultos publicadas no período de 2005-2016 no Boletim de Educação Matemática - BOLEMA, proporcionando conhecer mais sobre a área e permitindo uma visão panorâmica sobre os estudos. Temos consciência de que os dados aqui apresentados não podem ser considerados como uma afirmação fechada das características evidenciadas na Educação Matemática na EJA nos últimos dez anos, pois apresentamos somente dados de um único periódico.

Para apresentar um uma visão como um todo da área em estudo, seria necessário esgotar todos os espaços de divulgação científicas no referido período. Assim, poderíamos pesquisar o Banco de Teses e Dissertações de todos os Programas de Pós-Graduação e outros periódicos na área, assim como os Anais de eventos, por exemplo.

O levantamento, aqui efetivado, revelou-nos que as investigações que abordam a área de Educação Matemática na EJA são realizadas em partes por parcerias institucionais e interinstitucionais. Tais pesquisas apontam como foco temático mais evidente a busca pelo oferecimento de recursos ou propostas de ensino para este segmento de ensino e, também, quanto à formação de professores, assim como as compreensões e reflexões sobre a área de Educação Matemática.

Desse modo, organizamos nossas análises para melhor compreender a área de Educação Matemática da EJA em 4 aspectos :1) origens e quantitativo de autorias dos trabalhos 
selecionados;2) temáticas de aprofundamento; 3) metodologias empregadas; 4) a matemática abordada nas investigações.

Em relação à questão da origem dos trabalhos, percebemos que a maioria dos estudos foram elaborados coletivamente com um número de autores que varia de dois a quatro nas pesquisas que são realizadas em colaboração. Em relação às instituições, a qual os autores estão vinculados, todas são universidades públicas que desenvolvem pesquisas no campo da educação.

Quando a temática é a do aprofundamento, estão direcionados da seguinte maneira: a matemática abordada na EJA, reflexão sobre a abordagem interdisciplinar, percepção epistemológica dos professores de Matemática, problematização, educação financeira, valores socioeconômico, reflexões referentes ao raciocínio combinatório, práticas efetivas em educação matemática, gestão financeira, logística, atividades econômicas comunitárias, representação semiótica e desenvolvimento do pensamento estatístico.

Ao tratarmos das metodologias aplicadas, verificamos uma grande variedade, com destaque para textos que apresentam Discussões e Reflexões e Estudo de Caso, ambos os procedimentos presentes em seis trabalhos. Aplicação de Exame Diagnóstico, Estudo de Conteúdo, Análise Bibliográfica, Pesquisa Participante ou somente denominando de Pesquisa Qualitativa mostram que os pesquisadores em Educação Matemática na EJA, ora estudados, amparam-se prioritariamente em métodos qualitativos de pesquisa.

Entendemos que os estudos realizados na área de matemática buscam, dentro de suas probabilidades, uma aproximação em relação ao ensino e aprendizagem, diminuindo os problemas de docentes em ensinar, assim como o de estudantes em aprender. Verificamos, por meio desta análise, uma necessidade social de ensinarmos e melhorarmos o atendimento à EJA, para que os alunos possam assim como dito em versos de Silva e Da Silva (1975). "ter um lugar de mato verde e ou uma casinha de varanda" e com auxílio do estudo realizar seus sonhos.

Os resultados expostos, portanto, neste estudo, mostram-nos a necessidade de novas pesquisas voltadas a essa modalidade de ensino, que apresenta distinções e necessidades tão peculiares. 


\section{Referências}

BORGES, I. A.; JESUS, W. F. Financiamento da educação na EJA: contexto e desafio. In: CONGRESSO NACIONAL DE EDUCAÇÃO, 11., 2013. Anais [...]. Curitiba, set. 2013, p.1199 - 1211. Disponível em: https://educere.bruc.com.br/CD2013/pdf/6883_4306.pdf. Acesso em: 28 fev. 2019.

BRASIL. [Constituição (1988)]. Constituição da República Federativa do Brasil de 1988. Brasília, DF: Presidência da República. Disponível em:

http://www.planalto.gov.br/ccivil_03/constituicao/constituicao.htm. Acesso em: 1 fev.2019.

BRASIL. Ministério de Educação e Cultura. Lei no 9394/96, de 20 de dezembro de 1996 - LDB. Estabelece as diretrizes e bases da Educação Nacional. Brasília: MEC, 1996.

BRASIL. Parecer CNE no 11/2000: Disponível em:

http://portal.mec.gov.br/cne/arquivos/pdf/PCB11_2000.pdf. Acesso em: 20 fev. 2019.

BRASIL. Ministério da Educação. Educação para jovens e adultos: ensino fundamental: proposta curricular - 1ํo segmento. Brasilia: Ação Educativa, 2001.

CAPUCHO, V. Educação de Jovens e Adultos: práticas pedagógicas e fortalecimento da cidadania. São Paulo: Cortez, 2012.

CARVALHO, D. G.; BELLEMAIN, P. M. B. Ensino de área de figuras geométricas planas no currículo de matemática do Projovem Urbano. Bolema, Rio Claro, v.29, n.51, p.123-142, abr. 2015. DOI: https://doi.org/10.1590/1980-4415v29n51a07. Disponível em: https://www.scielo.br/scielo.php?script=sci_arttext\&pid=S0103636X2015000100008\&lng=pt\&nrm=iso. Acesso em: 20 jan. 2019.

CASAGRANDE DE OLIVEIRA, A. Como "ticas" de "matema" de cegos sob o viés institucional: da integração à inclusão. Bolema. Rio Claro, vol. 22, núm. 32, p.262-263, 2009. Disponível em: https://www.redalyc.org/articulo.oa?id=291221889019. Acesso em: 20 fev. 2019.

CONTI, K. C.; LUCCHESI DE CARVALHO, D. O letramento presente na construção de tabelas por alunos da Educação de Jovens e Adultos. Bolema, v.24, n.40, p.637-658, dez. 2011. Disponível em: https://www.redalyc.org/articulo.oa?id=2912/291222113002. Acesso em 20 fev. 2019.

CRECCI, V. M.; FIORENTINI, D. Gestão do currículo de matemática sob diferentes profissionalidades. Bolema, Rio Claro, v.28, n.49, p.601-620, ago. 2014. DOI:

https://doi.org/10.1590/1980-4415v28n49a07. Disponível em:

http://www.scielo.br/scielo.php?script=sci_arttext\&pid=S0103-

636X2014000200601\&lng=pt\&nrm=iso. Acesso em: 20 fev. 2020.

CRUZ DOS SANTOS, E. A etnomatemática no contexto do ensino inclusivo" [Reseña]. Bolema, 
Rio Claro, vol. 26, p.747-753, núm. 42 B, abr. 2012. Disponível em:

http://www.redalyc.org/articulo.oa?id=291223574017. Acesso em: 20 fev. 2019.

DE LIMA, M. J.; MONTEIRO, A. Práticas sociais de localização e mapeamento: uma discussão curricular sobre o conceito de escala. Bolema, Rio Claro, v.22, n.32, p.1-28, 2009. Disponível em: https://www.redalyc.org/articulo.oa?id=2912/291221889002. Acesso em: 20 jan. 2019.

DE SOUZA ROSA BORBA, R. E.; ARIMATÉA ROCHA, C.; AZEVEDO, J. Estudos em raciocínio combinatório: investigações e práticas de ensino na educação básica. Bolema, Rio Claro, v.29, n.53, p.1348-1368, dez. 2015. Disponível em:

https://www.redalyc.org/articulo.oa?id=2912/291243162028. Acesso em: 20 jan. 2019.

DONDA RODRIGUES, T. A etnomatemática no contexto do ensino inclusivo: possibilidades e desafios. Bolema, Rio Claro, v.21, n.30, 2008. Disponível em:

https://www.redalyc.org/articulo.oa?id=2912/291221878018. Acesso em: 20 fev. 2020.

FONSECA, A. G.; VILELA, D. S. Livros didáticos e apostilas: o currículo de matemática e a dualidade do ensino médio. Bolema, Rio Claro, v.28, n.49, p.557-579, ago. 2014. DOI: https://doi.org/10.1590/1980-4415v28n49a05. Disponível em: http://www.scielo.br/scielo.php?script=sci_arttext\&pid=S0103636X2014000200557\&lng=pt\&nrm=iso. Acesso em: 20 fev. 2019.

GEROMEL MENEGHETTI, R. C.; ZACHEO BARROFALDI, R. C. Práticas efetivas em educação matemática no contexto de um banco comunitário. Bolema, Rio Claro, v.29, n.53, dez. 2015, p.809-827. DOI: http://dx.doi.org/10.1590/1980-4415v29n53a02. Disponível em: https://www.redalyc.org/articulo.oa?id=2912/291243162003. Acesso em: 20 jan. 2019.

HADDAD, S.; DI PIERRO, M. C. Escolarização de jovens e adultos. Revista Brasileira de Educação, São Paulo, p.108-130. maio-ago. 2000. Disponível em: https://www.scielo.br/pdf/rbedu/n14/n14a07.pdf. Acesso em: 23 fevereiro 2019.

JANUARIO, G.; FREITAS, A. V.; LIMA, K. Pesquisas e documentos curriculares no âmbito da educação matemática de jovens e adultos. Bolema, Rio Claro, v.28, n.49, p.536-556, ago. 2014. DOI: http://dx.doi.org/10.1590/1980-4415v28n49a04. Disponível em: http://www.scielo.br/scielo.php?script=sci_arttext\&pid=S0103636X2014000200536\&lng=pt\&nrm=iso. Acesso em: 20 fev. 2019.

KNIJNIK, G., GLAVAM DUARTE, C. Entrelaçamentos e dispersões de enunciados no discurso da educação matemática escolar: um estudo sobre a importância de trazer a "realidade" do aluno para as aulas de matemática. Bolema, Rio Claro, v.23, n.37, p.863-886, dez. 2010. Disponível em: http://www.redalyc.org/articulo.oa?id=291221915002. Acesso em: 20 jan. 2019.

LIMA, I. B.; SELVA, A. C. V. Jovens e adultos construindo e interpretando gráficos. Bolema, Rio Claro, v.27, n.45, p.233-253, abr. 2013. DOI: http://dx.doi.org/10.1590/S0103636X2013000100012. Disponível em: http://www.scielo.br/scielo.php?script=sci_arttext\&pid= 
-636X2013000100012\&lng=pt\&nrm=iso. Acesso em: 20 fev. 2019.

MIRANDA REIS, P., SCHEID GAZIRE, E. A interdisciplinaridade no PROEJA: uma proposta possível no caderno temático Saúde e Números.

Bolema, v.27, n.46, p.481-496, ago. 2013. Disponível em:

http://www.redalyc.org/articulo.oa?id=291229373010. Acesso em: 20 jan. 2019.

OCAMPO, D. M.; SANTOS, M. E. T.; FOLMER, V. A interdisciplinaridade no ensino é possível? prós e contras na perspectiva de professores de matemática. Bolema, Rio Claro, v.30, n.56, p.1014-1030, dez. 2016. DOI: http://dx.doi.org/10.1590/1980-4415v30n56a09. Disponível em: http://www.scielo.br/scielo.php?script=sci_arttext\&pid=S0103636X2016000301014\&lng=pt\&nrm=iso. Acesso em: 20 fev. 2019.

PIRES, C. M. C. et al. O currículo de matemática em revista: um editorial. Bolema, Rio Claro, v.28, n.49, p.485-490, ago. 2014. DOI: http://dx.doi.org/10.1590/1980-4415v28n49e02.

Disponível em: http://www.scielo.br/scielo.php?script=sci_arttext\&pid=S0103636X2014000200485\&lng=pt\&nrm=iso. Acesso em: 20 fev. 2019.

PIRES, C. M. C. Reflexões sobre relações entre currículo, avaliação e formação de professores na área de educação matemática. Bolema, Rio Claro, v.29, n.52, p.473-492, ago. 2015. DOI: http://dx.doi.org/10.1590/1980-4415v29n52a03. Disponível em: http://www.scielo.br/scielo.php?script=sci_arttext\&pid=S0103636X2015000200004\&Ing=pt\&nrm=iso. Acesso em: 20 fev. 2019.

REIS DE MIRANDA, P.; SCHEID GAZIRE, E. Saúde e números: uma parceria de sucesso. Bolema, Rio Claro, v.26, n.42 B, p.609-626, abr. 2012. Disponível em: http://www.redalyc.org/articulo.oa?id=291223574010. Acesso: 20 fev. 2019.

ROMANOWSKI, J. P.; ENS, R. T. As pesquisas denominadas "Estado da Arte" em educação. Diálogo e Educação, Curitiba, v.6, n.19, p.37-50, set./dez. 2006.

SCANDIUZZI, P. P.; LÜBECK, M. Itinerários do grupo de estudo e pesquisa em etnomatemática e sua relação com a educação matemática. Bolema, Rio Claro, v.25, n.41, p.125-151, 2011. Disponível em: http://hdl.handle.net/11449/72996. Acesso: 20 fev. 2019.

SCHNEIDER, S. M.; FONSECA, M. C. F. R. Práticas laborais nas salas de aula de matemática da EJA: perspectivas e tensões nas concepções de aprendizagem. Bolema, Rio Claro, v.28, n.50, p.1287-1302, dez. 2014. DOI: https://doi.org/10.1590/1980-4415v28n50a14. Disponível em: http://www.scielo.br/scielo.php?script=sci_arttext\&pid=S0103636X2014000301287\&lng=pt\&nrm=iso. Acesso em: 19 fev. 2019.

SILVA, G. V.; DA SILVA, J. F. Casinha branca., Letras de músicas, 1975. disponível: https://m.letras.mus.br/roberta-campos/casinha-branca/ Acesso em 26 de fev. de 2019

TEIXEIRA BARRETO, M. F; O tempo vivido pelo alfabetizando adulto nas aulas de matemática. 
Boletim de Educação Matemática, v.19, n.25, p.154-155, 2006. Disponível em: http://www.redalyc.org/articulo.oa?id=291221859022. Acesso em: 19 fev. 2019.

UNESCO. Conferência Internacional de Educação de Adultos [VI: 2009, Belém, Brasil]. Marco de ação de Belém. Brasília: UNESCO/MEC, abril de 2010.

UNIVESP TV. 1 Video (30 min). Ensino superior: formação de professores para EJA - Silmara Campos e Nonato Miranda. Publicado pelo Canal Univesp TV, 2014. Disponivel em: https://www.youtube.com/watch?v=fOi9vD15124. Acesso em: 10 dez 2019.

Recebido em fevereiro 2020.

Aprovado em julho 2020. 